\title{
Magnitude and causes of mortality differences between married and unmarried men
}

\author{
Yoav Ben-Shlomo, George Davey Smith, Martin Shipley, M G Marmot
}

\begin{abstract}
Study objective-To determine the effect of marital status on mortality for men. In particular, to examine whether subgroups of unmarried men (widowed, single, and divorced/separated men) have a similar mortality to married men.

Design-Cohort study

Setting-Whitehall civil service, London, between 1967 and 1969

Participants-A total of 18403 men aged 40-64 years with 18 years' follow up.

Measurements and main results-Causespecific mortality rates and risk factors at baseline were determined. Overall mortality was greater for all groups of unmarried men. Patterns of mortality were different in the subgroups of unmarried men. Widowed men had a significantly greater risk of dying from ischaemic heart disease (relative risk (RR) $1 \cdot 46,95 \%$ confidence interval $(\mathrm{CI}) 1 \cdot 08,1.97)$ which persisted after exclusion of deaths that occurred in the first two years. Divorced men had greater cancer mortality (RR 1.49; 95\% CI 1.06, 2.10) that could not be explained simply by their greater consumption of cigarettes. The initial increased mortality for single men was no longer evident after adjustment for other risk factors, suggesting that single status in itself may not increase the risk. The risk for single men may have been underestimated, however, by over adjustment for possible intermediary factors.
\end{abstract}

Conclusions-Previous studies, which have examined total mortality only or have grouped all unmarried men, have masked interesting differences in the cause of death between subgroups of unmarried men. The extent to which the findings are explicable by psychosocial factors or the role of other environmental factors, which may also differ in relation to marital status, is unclear. Future work should not assume that all unmarried men have similar mortality risks and must examine the life course of each subgroup to advance our understanding of the possible causal role of marital status in disease aetiology.

\section{f Epidemiol Community Health 1993; 47: 200-205}

An association between marital status and mortality was noted as early as 1858 , when Farr observed that mortality rates for widowers were higher than expected. ${ }^{1}$ Routine statistics from many countries have consistently shown higher mortality for unmarried compared with married men. ${ }^{23}$ Cross sectional data are limited as the time sequence relating health and marital status cannot be disentangled. Prospective studies avoid this problem and show similar patterns of mortality. ${ }^{4-13}$ Most of these studies, however, have either had no adequate information on established risk factors ${ }^{4-6}{ }^{10}$ or have been based on relatively small cohorts and are therefore unable to examine cause-specific mortality in any detail. ${ }^{7-9} 11$ Attention has mainly been paid to mortality in widowers compared with married men ${ }^{101314}$ or has focused on the mortality of married versus unmarried men. ${ }^{7-9} 11$ This assumes that widowed, separated/divorced, and never married men will experience similar mortality, obscuring possible differences in these groups.

In disease aetiology, marriage may be both an acute stressor (for example the emotional trauma of widowhood or divorce) and a protector (for example, the social support provided by a spouse). ${ }^{15}$ Changes in neural, hormonal, and immunological control sytems in unmarried men have been postulated to result in a broad array of diseases. ${ }^{41617}$ This has led to the idea that unmarried men are more susceptible to ill health. ${ }^{16} 18$

This is a large cohort study of middle aged men, followed up for 18 years. It has collected data on marital status at baseline and on several important risk factors that may act as possible confounders or intermediaries in the relationship between marital status and mortality. It is therefore suitable for exploring whether a generalised increase in mortality for different causes is seen for all unmarried men, as predicted by the general susceptibility theory, and whether the increased risk seen in unmarried men is related to differences in established risk factors.

\section{Methods}

In the Whitehall study 18403 men aged 40-64 years were examined between 1967 and 1969 . Clinical measurements included height, weight, blood pressure, forced expiratory volume in one second $\left(\mathrm{FEV}_{1}\right)$, forced vital capacity (FVC), and a limb lead electrocardiogram.

Subjects were examined in the morning after an overnight fast and were given $50 \mathrm{~g}$ of oral glucose. Two hours later, a capillary blood sample was drawn for the measurement of glucose and cholesterol concentrations. Subjects with a plasma glucose $\geqslant 11.1 \mathrm{mmol} / 1$ ( $\geqslant 200 \mathrm{mg} / 100 \mathrm{ml})$ or with previously diagnosed diabetes consitituted the diabetic group, non-diabetic subjects with glucose concentrations above the 95th centile point $(5 \cdot 4-11.0 \mathrm{mmol} / \mathrm{l} ; 96-199 \mathrm{mg} / 100 \mathrm{ml})$ formed the 
group with impaired glucose tolerance, and subjects with values below this were considered to have normal glucose concentrations.

A questionnaire regarding age, marital status, civil service employment grade, and smoking habits was completed. Details of alcohol consumption were obtained from a $10 \%$ sample of men, who completed a three day dietary record. ${ }^{19}$

Marital status was defined as married, single, widowed, or other. The "other" category has been assumed to represent divorced/separated men and this label is used throughout.

There are four broad grades of employment in the civil service-administrators, professional and executive staff, clerical, and other (mainly unskilled manual) grades. In 873 subjects from the Diplomatic Service and British Council, employment grade was not comparable with the rest of the sample and these subjects have been kept as a separate group.

Smoking habit was categorised as "current smoker", "exsmoker", and "never smoker". In addition, adjustment for smoking habits included a term for the number of cigarettes per day smoked by current smokers. The 640 men who smoked pipes or cigars only have been treated as a separate group in the analyses that involve smoking status.

Disease at baseline was defined by any of the following: relative shortness of breath on level ground, pain in either leg on walking, past history of diabetes, heart or blood pressure trouble, unexplained weight loss over the preceding year, grade 1 or 2 angina according to the Rose angina questionnaire, severe chest pain for over half an hour and an abnormal resting ECG according to the following Minnesota code items: Q/QS waves $(1 \cdot 1-1 \cdot 3)$; ST depressions (4.1-4.4); T-wave inversion or flattening $(5 \cdot 1-5 \cdot 3)$; or left-bundle branch block $(7 \cdot 1)$. Full details of the procedures used have been previously reported. ${ }^{20}$

Records from over $99 \%$ of the subjects were flagged at the National Health Service Central Registry. Death certificates were coded according to the eighth revision of the International Classification of Diseases (ICD), and mortality data for 18 years follow up provides the basis for this analysis. Death has been classified as from coronary heart disease (CHD; ICD codes 410-414), cardiovascular disease (CVD; ICD codes 390458 ), cancer of the trachea, bronchus, and lung (ICD code 162), or any neoplasm (ICD codes 140-239), accident or violent death (ICD code 800-999). All-cause and mortality from causes other than cardiovascular disease and neoplasm have also been examined. Neoplasms have also been classified according to whether smoking is considered to have played a part in the

Table I Age adjusted mortality rates per 1000 person years by marital status (number of deaths in brackets)

\begin{tabular}{|c|c|c|c|c|}
\hline & $\begin{array}{l}\text { Married } \\
(n=15600)\end{array}$ & $\begin{array}{l}\text { Widowed } \\
(n=269)\end{array}$ & $\begin{array}{l}\text { Single } \\
(n=1536)\end{array}$ & $\begin{array}{l}\text { Other } \\
(n=296)\end{array}$ \\
\hline All causes & $13.9(3433)$ & $20 \cdot 6(109)$ & $16.9(387)$ & $21.0(89)$ \\
\hline Cardiovascular disease: & $7 \cdot 3(1821)$ & $10.0(59)$ & $8.5(195)$ & $8.4(36)$ \\
\hline Coronary heart disease & $5 \cdot 4(1348)$ & $8 \cdot 1(46)$ & $5 \cdot 2(123)$ & $5 \cdot 5(23)$ \\
\hline All cancer: & $4 \cdot 3(1080)$ & $5.9(29)$ & $4.6(103)$ & $8 \cdot 2(34)$ \\
\hline Lung cancer & $1.5(359)$ & $3 \cdot 0(12)$ & $2 \cdot 1(47)$ & $3 \cdot 2(13)$ \\
\hline Smoking-related neoplasms & $2 \cdot 4(588)$ & $4 \cdot 1$ (17) & $2.9(66)$ & $3.9(16)$ \\
\hline Non-smoking related neoplasms & $2 \cdot 0(492)$ & $1 \cdot 8(12)$ & $1.6(37)$ & $4 \cdot 2(18)$ \\
\hline $\begin{array}{l}\text { Non-cardiovascular/non-neoplastic } \\
\text { disease: }\end{array}$ & $2 \cdot 1(520)$ & $4.7(21)$ & $3.9(88)$ & $4 \cdot 5(19)$ \\
\hline Respiratory d & $1 \cdot 1(266)$ & $2 \cdot 0(11)$ & $2 \cdot 2(49)$ & $2 \cdot 4(10)$ \\
\hline Accidents and violence & $0.3(69)$ & $1 \cdot 4(4)$ & $0.6(15)$ & $0.4(2)$ \\
\hline
\end{tabular}

aetiology. ${ }^{21-23}$ The causes deemed to be smoking related (together with their ICD codes) are: malignant neoplasms of the lip (ICD 140), tongue (141), mouth and pharynx (143-149), oesophagus (150), pancreas (157), respiratory system neoplasms (160-163), urinary system neoplasms (188-189), and malignant neoplasms of unspecified site or secondary neoplasms (195199). All other neoplasms were classified as not related to smoking.

Mortality has been calculated according to person years at risk. These rates, and also all means and proportions, have been standardised for age by the direct method, using the total population as the standard. Differences in proportions and continuous variables in relation to marital status were tested using the CochranMantel-Haenszel statistic in $\mathrm{SAS}^{24}$ and by analysis of covariance respectively. Adjustment for risk factors and calculation of confidence intervals for the relative risks was done by Cox's proportional hazards regression model. ${ }^{25}$ Variations in the cause-specific odds ratios for unmarried men were tested using the $\chi^{2}$ test for heterogeneity. This was calculated initially for the simplest model and only the causes with a significant value were retested in later models. Differences in proportions of deaths in relation to marital status were tested using the $\chi^{2}$ test with Fisher's exact test if the expected value for a cell was less than five.

Whether an increased mortality risk could be explained by alcohol consumption was examined. We calculated the relative risk of mortality in data from the $10 \%$ sample for whom consumption data were available, and who were grouped into: nondrinkers, those who drank 0-34 units per week, and those who drank more than 34 units per week. The risk estimates were then applied to the total sample to calculate expected rate ratios, assuming the proportion of subjects in each drinking category was equivalent to that in the $10 \%$ sample.

\section{Results}

All the groups of unmarried men had higher total mortality than the married men (table I). The marital status, however, is that recorded at baseline; no data on change of status over the follow up period were available. The major cause of the excess risk seemed to vary, however, in relation to marital status group. The associations between marital status and other established risk factors are shown in table II. Married men had a more favourable risk factor profile than unmarried men for seven of the 11 variables. This was not true for serum cholesterol concentrations, body mass index, and systolic blood pressure. Proportional hazards models were calculated to examine relative mortality associated with marital status in relation to different causes. As some of the above risk factors may act either as possible confounders or may be intermediaries in the causal pathway between marital status and mortality, (for example, being divorced may result in smoking) we initially present relative rates adjusted only for factors that are unlikely to be secondary to marital status. Three different models were used: adjusting for age (table III), adjusting for age, height, and employment grade (table IV), and adjusting for other possible factors on which data 
Table II Age adjusted proportions and means for established risk factors in relation to marital status

\begin{tabular}{|c|c|c|c|c|c|}
\hline & Married & Widowed & Single & Other & Significance * \\
\hline Age & 51.5 & $55 \cdot 9$ & $50 \cdot 8$ & $51 \cdot 6$ & $\mathrm{p}<0.001$ \\
\hline \multicolumn{6}{|l|}{ Grade: } \\
\hline Administrative & $5 \cdot 6$ & $3 \cdot 6$ & $2 \cdot 5$ & $2 \cdot 7$ & \\
\hline Professional/Executive & $68 \cdot 6$ & $57 \cdot 9$ & $45 \cdot 5$ & $51 \cdot 1$ & \\
\hline Clerical & $13 \cdot 1$ & $24 \cdot 7$ & $31 \cdot 2$ & $25 \cdot 8$ & $\mathrm{p}<0.001$ \\
\hline Other & $7 \cdot 8$ & $13 \cdot 1$ & $16 \cdot 1$ & $14 \cdot 2$ & \\
\hline \multicolumn{6}{|l|}{ British Council and } \\
\hline Diplomatic Service & 4.9 & $0 \cdot 8$ & $4 \cdot 7$ & $6 \cdot 1$ & \\
\hline Cholesterol (mg/100ml) & $198 \cdot 2$ & $190 \cdot 1$ & $195 \cdot 1$ & $196 \cdot 5$ & $p=0.004$ \\
\hline \multicolumn{6}{|l|}{ Systolic blood } \\
\hline $\begin{array}{c}\text { pressure }(\mathrm{mmHg}) \\
\text { Body mass index }\left(\mathrm{kg} / \mathrm{m}^{2}\right)\end{array}$ & $135 \cdot 9$ & $135 \cdot 9$ & $137 \cdot 7$ & $133 \cdot 1$ & $\mathrm{p}<0.001$ \\
\hline \multicolumn{6}{|l|}{ Smoking status: } \\
\hline Never smoked & $22 \cdot 2$ & $20 \cdot 6$ & $23 \cdot 7$ & $16 \cdot 2$ & \\
\hline Exsmoker & $37 \cdot 3$ & $33 \cdot 3$ & $30 \cdot 4$ & $25 \cdot 0$ & $\mathrm{p}<0.001$ \\
\hline Current smoker & $40 \cdot 5$ & $46 \cdot 1$ & $45 \cdot 9$ & $58 \cdot 8$ & \\
\hline \multicolumn{6}{|l|}{ No of cigarettes per day } \\
\hline (smokers) & $15 \cdot 8$ & $16 \cdot 3$ & $18 \cdot 7$ & $18 \cdot 6$ & $\mathrm{p}<0.001$ \\
\hline \multicolumn{6}{|l|}{ Glucose tolerance } \\
\hline Impaired GTT & $5 \cdot 2$ & $6 \cdot 3$ & $7 \cdot 2$ & $4 \cdot 1$ & $\mathrm{p}<0.001$ \\
\hline Diabetic & $1 \cdot 1$ & 1.9 & $2 \cdot 3$ & $0 \cdot 7$ & $\mathrm{p}<0.001$ \\
\hline Disease at entry & $22 \cdot 4$ & $24 \cdot 3$ & $25 \cdot 4$ & $30 \cdot 0$ & $\mathrm{p}<0.001$ \\
\hline Height $(\mathrm{cm})$ & $176 \cdot 1$ & $174 \cdot 5$ & $174 \cdot 1$ & $175 \cdot 7$ & $\mathrm{p}<0.001$ \\
\hline Adjusted FEV $\mathrm{FV}_{1}$ (1) & $3 \cdot 18$ & $3 \cdot 16$ & 3.05 & 3.03 & $\mathrm{p}<0.001$ \\
\hline \multicolumn{6}{|l|}{ Alcohol consumption $\dagger$} \\
\hline Non-drinkers & $32 \cdot 6$ & $32 \cdot 6$ & $38 \cdot 6$ & $37 \cdot 9$ & \\
\hline Mild/moderate & $54 \cdot 9$ & $51 \cdot 5$ & $44 \cdot 6$ & $32 \cdot 4$ & $\mathrm{p}=0.04$ \\
\hline Heavy $>34 \mathrm{U} / \mathrm{wk}$ & $12 \cdot 5$ & $15 \cdot 9$ & $16 \cdot 8$ & $29 \cdot 7$ & \\
\hline
\end{tabular}

*Cochran-Mantel-Haenzsel test of heterogeneity for categorical variables, analysis of

covariance for continuous variables.

tAlcohol data only based on a $10 \%$ sample of the study

GTT=glucose tolerance test; FEV $_{1}=$ forced expiratory volume in one second.

were available (table V). Rate ratios and 95\% confidence intervals are shown for each marital status group relative to married men.

All unmarried men had significantly higher total mortality than married men, although single men no longer had a statistically significant increased risk after adjustment for coronary heart disease only widowed men had a significantly increased mortality rate, which was little altered by adjustment. Divorced/separated men had a greater risk of both neoplasm and death from causes other than cardiovascular or neoplastic diseases. Violent and accidental deaths were increased in all unmarried groups, although this remained significant only for single men. In the unmarried groups, a $\chi^{2}$ test for heterogeneity between the odds ratios was significant for al cancers $\left(\chi^{2}=7 \cdot 9\right.$ on $\left.2 \mathrm{df} p=0.02\right)$ and non-smoking related cancers $\left(\chi^{2}=10 \cdot 42\right.$ on $\left.2 \mathrm{df} p=0.006\right)$. The latter remained significant even after adjusting for

Table III Age adjusted mortality ratios (95\% confidence intervals) for marital status relative to married men $(n=17701)$

\begin{tabular}{|c|c|c|c|}
\hline & Widowed & Single & Other \\
\hline All causes & $.31(1.08,1.59)$ & $1 \cdot 25(1.13,1.39)$ & $1.54(1.24,1.90)$ \\
\hline Card & & $1 \cdot 19$ & .63) \\
\hline Cor & $3,1.9$ & $1.01(0.84,1 \cdot 21)$ & $1.00(0.66,1.51)$ \\
\hline All cancers: & $7,1 \cdot 62)$ & $1.06(0.87,1.30)$ & $1.86(1.32,2.61)$ \\
\hline Lung cancer & $0,2 \cdot 23)$ & $1.46(1.08,1.98)$ & $2.15(1.24,3.74)$ \\
\hline Smo & 5) & $7,1 \cdot 61)$ & $8,2 \cdot 65)$ \\
\hline Non- & $\cdot 62,1.94)$ & $0.83(0 \cdot 59,1 \cdot 16)$ & $2 \cdot 14(1 \cdot 34,3 \cdot 4$ \\
\hline \multirow{2}{*}{\multicolumn{4}{|c|}{$\begin{array}{l}\text { Non-cardiovascular/non-neoplastic } \\
\text { disease: }\end{array}$}} \\
\hline & & & \\
\hline Respiratory disease & & & \\
\hline Accidents and violence & ) & $2 \cdot 2$ & $1.63(0.4 c$ \\
\hline
\end{tabular}

Table IV Mortality ratios (95\% confidence intervals) for marital status relative to married men adjusted for age, grade, and height $(n=17701)$

\begin{tabular}{llll}
\hline & Widowed & Single & Other \\
\hline All causes & $1.20(1.00,1.46)$ & $1.11(1.00,1.24)$ & $1.43(1 \cdot 16,1.76)$ \\
Cardiovascular disease: & $1.24(0.95,1.61)$ & $1.08(0.93,1.25)$ & $1.11(0.80,1.55)$ \\
$\quad$ Coronary heart disease & $1.34(1.00,1.81)$ & $0.91(0.76,1.10)$ & $0.96(0.64,1.45)$ \\
All cancers: & $1.05(0.73,1.52)$ & $0.96(0.78,1.18)$ & $1.71(1.22,2.41)$ \\
$\quad$ Lung cancer & $1.10(0.62,1.96)$ & $1.20(0.88,1.64)$ & $1.83(1.05,3.18)$ \\
$\quad$ Smoking related cancers & $1.02(0.63,1.66)$ & $1.06(0.82,1.38)$ & $1.43(0.87,2.35)$ \\
$\quad$ Non-smoking related cancers & $1.09(0.61,1.95)$ & $0.83(0.59,1.16)$ & $2.09(1.31,3.36)$ \\
Non-cardiovascular/non-neoplastic & & & \\
$\quad$ disease: & $1.37(0.88,2 \cdot 12)$ & $1.51(1.20,1.90)$ & $1.93(1.22,3.06)$ \\
$\quad$ Respiratory disease & $1.16(0.63,2.13)$ & $1.51(1.11,2.07)$ & $1.96(1.04,3.69)$ \\
Accidents and violence & $2.98(1.07,8.30)$ & $2.02(1.13,3.60)$ & $1.53(0.37,6.27)$ \\
\hline
\end{tabular}

all other factors. The $\chi^{2}$ test for heterogeneity for coronary heart disease did not reach conventional significance level $\left(\chi^{2}=4 \cdot 50\right.$ on $\left.2 \mathrm{df} p=0 \cdot 11\right)$.

Heavy alcohol consumption may be important in several categories of mortality for divorced/ separated men, as this group had the greatest proportion of heavy drinkers. Extrapolating the data from the $10 \%$ sample suggested that alcohol consumption may account for around $30 \%$ and $21 \%$ of the excess mortality from respiratory and non-cardiovascular/non-neoplastic diseases respectively in divorced/separated men but only for $12 \%$ and $9 \%$ respectively in non-smoking related neoplasms and all cancers. As the number of events from this subsample are small, however, these estimates should be interpreted cautiously.

Prostatic cancer was the most common cause of death from non-smoking related neoplasms in divorced/separated men. This was more likely to occur in divorced/separated men than in married men $(39 \%$ versus $16 \%$ of all cancers, $p=0.022)$.

To examine whether the increase in coronary heart disease mortality for widowed men was a sudden phenomenon brought on by bereavement, the age adjusted rate ratios were recalculated after excluding any deaths in the first two years of follow up. The rate ratio was hardly changed at 1.44 (95\% CI 1.06, 1.96).

\section{Discussion}

We have presented the risk of mortality based on three different models. The appropriateness of adjusting for a confounding factor depends on whether that factor is related to both marital status and mortality but is not an intermediary in the causal pathway. In the latter case, adjustment could result in underestimation of the apparent influence of marital status. As the extent to which these considerations are valid for some of the variables is unclear, we have presented all three models. For example, smoking habit is usually established before people get married. In this cohort the mean age of starting to smoke was 18.3 years and this did not differ in relation to marital status. The persistence of this habit, however, could depend upon marital status, since having the support of a partner might encourage someone to give up. ${ }^{26}$ The degree to which smoking behaviour should be treated as a simple confounder is not easy to evaluate. If the beneficial effects of marriage for men act through change in risk factors such as smoking, then the results presented in the final model may understate the importance of marital status. It is believed, however, that marriage is beneficial through psychosocial mechanisms over and above any effect of a change in lifestyle. In this case it is reasonable to examine mortality risk after adjusting for such variables as smoking habit. Until there is more research on the effects of marital status on lifestyle, its importance in influencing other risk factors remains unknown.

As expected, the married men show lower all-cause mortality than unmarried men. Unlike other studies, however, patterns of mortality differed in relation to marital status groups.

The increased risk of death for widowed men was mainly attributable to coronary heart disease. This was not simply a phenomenon that occurred 
as a result of bereavement, as suggested by some studies, ${ }^{1013}$ as the increase was similar after deaths during the first two years of follow up were excluded.

In contrast, divorced/separated men had an increased risk of mortality from neoplasm-both from smoking and non-smoking related neoplasms. The former was unsurprising as divorced/ separated men were more likely to be heavy smokers. This risk was greatly reduced by adjusting for smoking status as well as other risk factors. The risk associated with non-smoking related neoplasms was hardly altered by adjusting for confounding factors and is unlikely to have differed even if we had controlled for alcohol consumption. The most important cause of death in this group of neoplasms was prostatic cancer. An increased risk of prostatic cancer in divorced/ separated men has been found in some ${ }^{27} 28$ but not all studies ${ }^{29}$ and may be related to increased sexual activity. ${ }^{30}$ The increased risk seen for respiratory and non-cardiovascular/non-neoplastic deaths in divorced/separated men might have been greatly reduced (by $30 \%$ and $21 \%$ respectively) if alcohol consumption could have been adjusted for in the analysis.

Single men initially showed an increased risk for all-cause mortality. These men were of lower employment grade, shorter stature, and had more disease at baseline. Both employment grade ${ }^{31} 32$ and height ${ }^{31} 33$ are known to be powerful predictors of mortality. Because height is also associated with perceived physical attractiveness, ${ }^{34}$ the apparently increased mortality risk in the single men could be a result of selection into marital status categories. After adjustment, the increased risk for total mortality fell considerably and was no longer statistically significant. This suggests that being single by itself is not associated with increased mortality, but the effect of remaining single on risk factors such as blood pressure and smoking, both high in this group compared with married men, cannot be ruled out. The high risks for non-cardiovascular/non-neoplastic and respiratory diseases were reduced after smoking and other risk factors had been adjusted for. In a multivariate analysis full adjustment is limited because of measurement imprecision, ${ }^{35}$ and using more precise measures would probably reduce further the seemingly increased risk.

Our results are limited in several ways. Firstly, marital status was recorded at baseline only and subjects may have become widowed, separated, or remarried over the follow up period. Data from the longitudinal study ${ }^{36}$ which covered a similar period (1971-1981) but limited to 10 years

Table $V$ Mortality ratios (95\% confidence intervals) for marital status relative to married men adjusted for age, grade, height, body mass index, smoking, systolic blood pressure, cholesterol, impaired glucose tolerance, diabetes, forced expiratory volume in one second, forced vital capacity, and disease at entry $(n=17701)$

\begin{tabular}{|c|c|c|c|}
\hline & Widowed & Single & Other \\
\hline All causes & $1.24(1.02,1.51)$ & $1.05(0.94,1.17)$ & $1 \cdot 24(1.00,1.54)$ \\
\hline Cardiovascular disease: & $1.33(1.02,1.72)$ & $1.01(0 \cdot 8$ & $\cdot 68,1 \cdot 34)$ \\
\hline Coronary heart disease & $1.46(1.08,1.97)$ & $0.86(0.71$ & $\cdot 54,1 \cdot 26)$ \\
\hline All cancers: & $1.07(0.74,1.55)$ & $0.92(0.75,1.13)$ & $1.49(1.06,2 \cdot 10)$ \\
\hline Lung cancer & $1.10(0.62,1.97)$ & $1.11(0.81,1.52)$ & $1.44(0.83,2.51)$ \\
\hline Smoking related & $4,1 \cdot 69)$ & $0.99(0.76,1.29)$ & $1.17(0.71,1.93)$ \\
\hline Non-smoking related cancers & $1.11(0.62,1.98)$ & $0.82(0.59,1.16)$ & $1.98(1.23,3 \cdot 18)$ \\
\hline \multirow{4}{*}{$\begin{array}{l}\text { Non-cardiovascular/non-neoplastic } \\
\text { disease: } \\
\text { Respiratory disease } \\
\text { Accidents and violence }\end{array}$} & & & \\
\hline & $1 \cdot 36(0 \cdot 86,2 \cdot 13)$ & $1.36(1.08,1.72)$ & $1.64(1.03,2.60)$ \\
\hline & $1.27(0.69,2.35)$ & $1.37(1.00,1 \cdot 88)$ & $1.64(0.87,3.09)$ \\
\hline & $2 \cdot 76(0.98,7 \cdot 73)$ & $1.94(1.09,3.47)$ & $1.33(0.32,5.47)$ \\
\hline
\end{tabular}

follow up, provide some evidence of changing marital status. For men between the ages of 45-59 years, $91 \%$ of married men were still married, $4.6 \%$ were widowed, and $2.5 \%$ were divorced or separated. In unmarried men, only $0.9 \%$ of divorced men and $1.0 \%$ of widowers remarried. With 18 years' follow up it is likely that a greater proportion of married men will have become widowed, therefore any misclassification of marital status will probably affect this group. We have also assumed that divorced or separated men would have responded to the "other" category rather than "single". Both these potential misclassifications will reduce the likelihood of finding true differences between different marital status subgroups, thereby making our significant findings even more important. Secondly, no data were collected specifically on social networks. From all the measures used to give a social network indicator, marital status seems to be the most important in younger age groups in both univariate $^{79}$ and multivariate analyses ${ }^{11}$ and is weighted more heavily than other factors in the Alameda study social network index ${ }^{8}$ a multidimensional score that has been shown to predict mortality. Thirdly, we have estimated the effect of adjusting for alcohol consumption on the risk by using the data from our $10 \%$ subsample. These results should be treated cautiously as the rate ratios were based on a small number of events

Previous reports examining social relationships have usually only examined all-cause mortality, either for pragmatic reasons or because all-cause mortality was felt to be a "more appropriate dependent variable". ${ }^{11}$ Similar findings are reported by the few studies with data on other risk factors, consistently less favourable in unmarried men, ${ }^{12} 3738$ and which examine unmarried men by subgroups. ${ }^{12}{ }^{39}$ Rosengren et $a l^{12}$ found, after adjustment, a non-significant higher risk of cancer mortality in divorced than married men. Widowed men had an increased risk of coronary heart disease and single men had an increased risk from "other causes" but only univariate risks were presented. Several studies, ${ }^{5101240}$ but not all, ${ }^{4}$ have reported an increased risk of coronary heart disease for widowed men. Kaprio et $\mathrm{al}^{13}$ found a significant increase in coronary heart disease mortality only when men under the age of 65 years were considered (data recalculated), with an increase seen consistently across all five years of follow up. Jones $e t a l^{41}$ did not find a significant increase in deaths from neoplasm for widowed or divorced men, although the latter had a greater risk. These results were based on a large cohort but with no data on other factors such as smoking. Moss (cited in ${ }^{42}$ ), found that excess cancer rates were associated with marital separation. Violent and accidental deaths have been noted to occur more frequently in widowed men. ${ }^{24613}$

Why widowers should be more likely to die of coronary heart disease and divorced/separated men from some types of cancer is not obvious. Possible explanations are as follows:

(a) Chance. Although the relationships between widowhood and coronary heart disease has been seen in several studies, our finding of non-smoking related neoplasms in divorced/separated men may be a chance finding secondary to subgroup analysis. 
(b) Artefact. While variations in seeking medical advice and therefore diagnosis and death certification practice may exist for different marital status groups, it is unlikely that these could explain such specific patterns.

(c) Stress differences. The stresses associated with widowhood and subsequent loss of support may differ in widowers and divorced/separated men. Divorce or separation may be preceded by a period of marital disharmony enabling alternative support systems to be established.

(d) Personality. Men who get divorced or separated may have a different premorbid personality. Lack of closeness to parents ${ }^{43}$ and emotional suppression (type $\mathrm{C}$ personality) ${ }^{44}$ have both been associated with an increased risk of cancer and the inability to maintain social relationships ${ }^{45}$ may result in divorce.

(e) Lifestyle. Marital status categories have different lifestyles, either in childhood, early adulthood, or post bereavement or separation that result in greater exposure to other risk factors for coronary heart disease and neoplasms.

Our results could be taken as supporting the hypothesis that psychosocial factors play an independent role in the aetiology of some diseases, although this excess mortality could still reflect either residual confounding from poorly measured risk factors or the failure to include other explanatory variables. The different patterns of mortality found for each marital status group cannot be explained by a simple theory of general susceptibility, as unmarried men showed increased susceptibility only to some causes of death. This does not preclude the possibility that unmarried men do have greater susceptibility as a consequence of their marital status, but the exact cause of death is determined by factors that differ in prevalence across subgroups. Surprisingly, even the broad category of total cancer mortality showed an increase in risk only for divorced/separated men.

The increase in mortality from a wide range of causes seen for lower socioeconomic groups has also been used to support the concept of general susceptibility. ${ }^{31}$ However, for cancer deaths, only some cancers show this association, while others either have no association or show the opposite pattern. ${ }^{46}{ }^{47}$ These findings are of interest as the theory of immunosurveillance has been postulated as a link between socioeconomic or marital status and carcinogenesis. ${ }^{45} 48$

The utility of current theories of general susceptibility in explaining specific causes of death are limited without further refinements that can be supported empirically. Future research should examine if widowhood and divorce have different effects on biological functions such as the immune system, or whether other risk factors associated with cancer are more commonly found in divorced/separated men. It should not treat unmarried men as a homogeneous group and should explore differing life-courses, biological parameters, and causes of death, rather than just total mortality. In particular, increased mortality after a separation or divorce should be examined and the effects of "support" should be evaluated.

Dr Yoav Ben-Shlomo is a Wellcome Fellow in Clinical Epidemiology.
1 Farr W. Influence of marriage on the mortality of the French people. London: Savill and Edwards, 1859.

2 Koskenvuo M, Sarna S, Kaprio J, Lonnqvist J. Causespecific mortality by marital status and social class in Finland during 1969-1971. Soc Sci Med 1979; 13A: 691-7.

3 Hu YR, Goldman N. Mortality differentials by marital status: an international comparison. Demography 1990; 27: 233-50.

4 Helsing KJ, Comstock GW, Szklo M. Causes of death in a widowed population. Am $\mathcal{f}$ Epidemiol 1982; 116: 524-32.

5 Koskenvuo M, Kaprio J, Kesaniemi A, Sarna S. Differences in mortality from ischaemic heart disease by marital status in mortality from ischaemic heart disease by marial class. 7 Chron Dis 1980; 33: 95-106.

6 Kraus AS, Lilienfeld AM. Some epidemiologic aspects of the high mortality rate in the young widowed group. $\mathcal{F}$ Chron Dis high mortality rate in

7 Seeman TE, Kaplan GA, Knudsen L, Cohen R, Guralnik J. Social network ties and mortality among the elderly in the Alameda county study. Am $\mathcal{F}$ Epidemiol 1987; 126: 714-23.

8 Berkman LF, Syme SL. Social networks, host resistance and mortality: a nine-year follow-up of Alameda County residents. Am $\mathcal{f}$ Epidemiol 1979; 109: 186-204.

9 Schoenbach VJ, Kaplan BH, Fredman L, Kleinbaum DG Social ties and mortality in Evans County, Georgia. Am $\mathcal{F}$ Epidemiol 1986; 123: 577-91.

10 Murray Parkes C, Benjamin B, Fitzgerald RG. Broken heart: a statistical study of increased mortality among widowers. BMF 1969; 1: 740-3.

11 House JS, Robbins C, Metzner HL. The association of social relationships and activities with mortality: prospective evidence from the Tecumseh community health study. $A m \mathcal{F}$ Epidemiol 1982; 116: 123-40.

12 Rosengren A, Wedel H, Wilhelmsen L. Marital status and mortality in middle-aged Swedish men. Am 7 Epidemiol 1989; 129: 54-64.

13 Kaprio J, Koskenvuo M, Rita $H$. Mortality after bereavement: a prospective study of 95,647 widowed bereavement: a prospective study of 95,647

14 Helsing KJ, Szklo M, Comstock GW. Factors associated with mortality after widowhood. Am $\mathcal{F}$ Public Health 1981; 71: 802-9.

15 Susser $M$. Widowhood: a situational life stress or a stressful life event. Am F Public Health 1981; 71: 793-5.

16 Berkman LF. The relationship of social networks and social support to morbidity and mortality. In: Cohen S, Syme LS, eds. Social support and health. London: Academic Press, 1985: 241-62.

17 Berkman LF. Social networks, support and health: taking the next step forward. Am $\mathcal{F}$ Epidemiol 1986; 123: 559-62.

18 Cassel J. The contribution of the social environment to host resistance. Am ₹ Epidemiol 1976; 104: 107-23.

19 Marmot MG, Rose G, Shipley MJ, Thomas BJ. Alcohol and mortality: A U-shaped curve. Lancet 1981; i: 580-3.

20 Reid DD, Brett GZ, Hamilton PJS, Jarrett RJ, Keen H, Rose G. Cardiorespiratory disease and diabetes among middleaged male civil servants. Lancet 1974; i: 469-73.

21 Doll R, Peto R. Mortality in relation to smoking: 20 years' observations on male doctors. $B M \mathcal{F}$ 1976; ii: $1523-36$.

22 observations on male doctors. $B M 7$ 1976; ii: $1523-36$. million men and women. In: Haenzel W, ed. Epidemiological approaches to the study of cancer and other chronic diseases approaches to the study of cancer and other chronic diseases Bethesda, MD: National Cancer Institute, 1966:
Cancer Institute Monograph no 19. 127-204.

23 IARC. Tobacco smoking. Lyon: IARC, 1986. Monographs on the evaluation of the carcinogenic risk of chemicals to humans, vol 38 .

24 SAS. SAS user's guide: statistics. Cary, NC: SAS Institute Inc,

25 Cox DR. Regression models and life tables. $f R$ Stat Soc $B$ 1972; 34: 187-220.

26 Mermelstein R, Cohen S, Lichtenstein E, Baer JS, Kamarck T. Social support, smoking cessation and maintenance. fournal of Consulting and Clinical Psychology 1986; 54: 447-453.

27 King H, Diamond E, Lilienfeld AM. Some epidemiological aspects of cancer of the prostate. F Chron Dis 1963; 16: 117-53.

28 Ernster VL, Sacks ST, Selvin S, Petrakis NL. Cancer incidence by marital status: US Third National Cancer incidence by marital status: US Third Nation

29 Newell GR, Pollack ES, Spitz RM, Sider JG, Fueger JJ. Incidence of prostate cancer and marital status. $\mathcal{F}$ Natl Incidence of prostate cancer
Cancer Inst 1987; 79: 259-62.

Cancer Inst 1987; 79: 259-62.
30 Flanders WD. Review: prostate cancer epidemiology. Prostate 1984; 5: 621-9.

31 Marmot MG, Shipley MJ, Rose G. Inequalities in deathspecific explanations of a general pattern?. Lancet 1984; i: 1003-6.

32 Davey Smith G, Shipley MJ. Rose G. Magnitude and causes of socioeconomic differentials in mortality: further evidence from the Whitehall study. $\mathcal{F}$ Epidemiol Community Health 1990; 44: 265-70.

33 Waaler HT. Height, weight and mortality: the Norwegian experience. Acta Medica Scandinava 1984; 679 suppl: $1-56$.

4 Macintyre S, West P. Social, developmental and health correlates of "attractiveness" in adolescence. Sociology of Health and Illness 1991; 13: 152-67.

35 Phillips AN, Davey Smith G. How independent are "independent" effects? Relative risk estimation when correlated exposures are measured imprecisely. $f$ Clin correlated exposures are meast

36 Bhrolchain MN. Changing partners; a longitudinal study of marriage: a study of remarriage based on the OPCS longitudinal study. Population Trends 1988; 53: 27-34. 
37 Weiss NS. Marital status and risk factors for coronary hear disease: the United States health examination of adults. $B r f$ Prev Soc Med 1973; 27: 41-3,

38 Venters M, Jacobs DR, Pirie P, Luepker RV, Folsom AR Gillum RF. Marital status and cardiovascular risk: The Minnesota heart survey and the Minnesota heart health program. Psychosom Med 1986; 15: 591-605.

39 Kotler P, Wingard DL. The effect of occupational, marital and parental roles on mortality: The Alameda County study. Am ₹ Public Health 1989; 79: 607-11.

40 Jones DR. Heart disease mortality following widowhood: some results from the OPCS longitudinal study. $\mathcal{F}$
Psychosoma Res $1987 ; 31: 325-33$.

41 Jones DR, Goldblatt PO, Leon DA. Bereavement and cancer: some data on deaths of spouses from the Surveys. BMF 1984; 289: 461-4.

42 Reed D, MgGee D, Yano K. Psychosocial processes and general susceptibility to chronic disease. Am $\mathcal{f}$ Epidemiol general susceptibility
43 Thomas CB. Precursors of premature disease and death. Ann Intern Med 1976; 85: 653-8.

44 Greer S, Watson M. Towards a psychobiological model of cancer: psychological considerations. Soc Sci Med 1985; 20 : 773-7.

45 Baltrusch HJF, Waltz M. Cancer from a biobehavioural and social epidemiological perspective. Soc Sci Med 1985; 20 : 789-94.

46 Davey Smith G, Leon D, Shipley MJ, Rose G. Socioeconomic differentials in cancer Epidemiol 1991; 20: 339-45.

47 Rimpela AH, Pukkala EI Cancers of affluence: positive cancer forms. Soc Sci Med 1987; 24: 601-6. 48 cancer forms. Soc Sci Med 1987; 24: 601-6.

psy T, Mackay C. Psychosocial factors and psychophysiological mechanisms in the aetiology and
development of cancers. Soc Sci Med 1982; 16: 381-6. 